\title{
O ensino de Antropologia Física e Etnografia do Brasil em Santa Catarina na década de 1950
}

The teaching of Physical Anthropology and Ethnography of Brazil in Santa Catarina in the 1950s

\section{Amurabi Oliveira}

\section{(2) OpenEdition}

Journals

\section{Edição electrónica}

URL: https://journals.openedition.org/aa/4983

DOI: $10.4000 /$ aa. 4983

ISSN: 2357-738X

\section{Editora}

Programa de Pós-Graduação em Antropologia Social (UnB)

Edição impressa

Paginação: 269-286

ISSN: 0102-4302

\section{Refêrencia eletrónica}

Amurabi Oliveira, «O ensino de Antropologia Física e Etnografia do Brasil em Santa Catarina na década de 1950», Anuário Antropológico [Online], v.45 n. 1 | 2020, posto online no dia 27 janeiro 2020 consultado o 22 julho 2022. URL: http://journals.openedition.org/aa/4983 ; DOI: https://doi.org/ 10.4000/aa.4983

\section{(c) (i) (9)}

Creative Commons - Atribuição-NãoComercial-SemDerivações 4.0 Internacional - CC BY-NC-ND 4.0 https://creativecommons.org/licenses/by-nc-nd/4.0/ 


\title{
O ensino de Antropologia Física e Etnografia do Brasil em Santa Catarina na década de 1950
}

The teaching of Physical Anthropology and Ethnography of Brazil in Santa Catarina in the 1950 s

DOI: https://doi.org/10.4000/aa.4983

\begin{abstract}
Amurabi Oliveira - Universidade Federal de Santa Catarina - Brasil
Doutor em Sociologia pela Universidade Federal de Pernambuco. Professor da Universidade Federal de Santa Catarina e Pesquisador do CNPq. Atualmente é professor visitante na Universidade Autônoma de Barcelona, por meio do programa PVE Junior CAPES.
\end{abstract}

Este artigo visa contribuir para o debate sobre a história da antropologia no Brasil, destacando o ensino das cadeiras de antropologia física e etnografia no Brasil na Faculdade Catarinense de Filosofia na década de 1950. A análise incide sobre os relatórios de ensino produzidos pelos primeiros professores dessas disciplinas em Santa Catarina, possibilitando o desenvolvimento de uma reflexão a partir dos conteúdos lecionados naquele contexto. Enfatiza-se que apesar do "apagamento" dessas matérias na história da antropologia, tanto em nível local quanto nacional, elas $\mathrm{O}$ ensino de Antropologia Física e Etnografia do Brasil em Santa Catarina na década de 1950 foram relevantes na constituição do campo da antropologia, demarcando continuidades e também rupturas em relação à antropologia cultural.

História da antropologia. Ensino de antropologia. Ensino de ciências sociais. Antropologia física. Etnografia do Brasil.
This paper aims to contribute to the debate on the history of anthropology in Brazil, highlighting the teaching of the chairs of physical anthropology and ethnography of Brazil at the Catarinense College of Philosophy in the 1950s. The analysis focuses on the teaching reports produced by the first professors of these disciplines in the state of Santa Catarina, enabling the development of a reflection based on the contents taught in that context. It is emphasized that despite the obliteration of these disciplines in the history of anthropology, both at local and national level, they were relevant in the constitution of the field of anthropology, marking continuities and ruptures in relation to cultural anthropology.

History of anthropology. Anthropology teaching. Social science teaching. Physical anthropology. Ethnography of Brazil. 


\section{Introdução}

Quando nos referirmos à história da antropologia brasileira, normalmente nos remetemos a um modelo que se tornou relativamente hegemônico no campo universitário, que se vincula a certa antropologia social e cultural. Esta concepção pode ser compreendida também a partir das próprias relações acadêmicas que a antropologia teceu desde sua gênese nas universidades, de maneira bastante próxima com a sociologia (Peirano, 2000), encontrando nos cursos de ciências sociais o espaço para sua institucionalização, produção e reprodução de profissionais específicos neste campo de conhecimento.

Todavia, a história da antropologia no Brasil não se resume à história da antropologia social e cultural, tampouco à presença dessa ciência nos cursos de ciências sociais. Já no final do século XIX, desenvolveu-se aqui toda uma tradição intelectual a partir do que ficou conhecido como antropologia física ${ }^{1}$, cujas influências teóricas e objetivos de pesquisa distavam sensivelmente desta outra antropologia. Espaços como Faculdades de Medicina e de Direito, Escolas Normais, Museus de História Natural ou mesmo Gabinetes Policiais formavam um locus privilegiado para o desenvolvimento do debate específico nesta área.

A disciplina de antropologia física, também em conjunto com outras correlatas, constituiu a base formativa de outros cursos de graduação. Não ficando restrita apenas à medicina e ao direito, fez-se presente em cursos de formação de professores, tanto no curso normal quanto nos cursos superiores.

Partindo dos "relatórios de ensino" 2 produzidos pelos primeiros catedráticos da Faculdade Catarinense de Filosofia (FCF) entre 1956 e $1959^{3}$, o presente artigo visa trazer uma contribuição original para o debate acerca da história da antropologia no Brasil. Ao mesmo tempo, busca ampliar o escopo geográfico da análise, ao deslocar o exame empírico para uma instituição fora dos grandes centros, em um período que antecedeu à criação dos primeiros cursos de ciências sociais na região. Volto-me, portanto, não para a antropologia cultural que fora lecionada nessa instituição nesse mesmo período, mas sim para as disciplinas de antropologia física e etnografia do Brasil.

Almeja-se neste trabalho explorar quais conteúdos eram lecionados nessas duas disciplinas, problematizando em que medida eles demarcam continuidades e descontinuidades em relação à perspectiva que se convencionou adotar acerca da história da antropologia no Brasil. Com isso, para além de uma colaboração particular ao campo da história da antropologia no Brasil, busca-se também contribuir de forma mais ampla para o campo da história da ciência.

Para uma melhor compreensão do leitor sobre as questões que serão abordadas aqui, dividirei o trabalho em quatro partes. São elas: a) breve contextualização sobre a antropologia física no Brasil; b) apresentação sucinta do processo de formação da FCF; c) análise dos relatórios de ensino das disciplinas de antropologia física e etnografia do Brasil; d) considerações finais.
1 Atenta-se aqui, desde já, que a terminologia "antropologia física" fora bastante recorrente até meados do século XX, tendo sido paulatinamente substituída pelos termos Antropologia Biológica ou Bioantropologia. Todas as três terminologias indicam um mesmo campo, mas se referem a momentos históricos distintos.

2 Essa documentação encontra-se disponível para consulta no Arquivo Central da Universidade Federal de Santa Catarina.

3 O material empírico do qual parte são os arquivos da FCF depositados no arquivo central da Universidade Federal de Santa Catarina (UFSC), o que inclui não apenas os "relatórios de ensino", como também diver sas atas, ofícios e memorandos produzidos pelos agentes que integraram esta instituição. 


\section{A antropologia física no Brasil}

Pensar a história da antropologia física no Brasil nos remete, inevitavelmente, a uma reflexão mais apurada acerca do lugar dos museus no processo de institucionalização das ciências sociais brasileiras, especialmente da antropologia. Ainda que a emergência dessas instituições datem do Brasil Imperial, é na passagem para o século XX que encontramos seu apogeu, que se vincula, em grande medida, ao debate sobre a questão racial no país. Analisando os casos do Museu Nacional, fundado em 1818, Museu Paraense de História Natural (atual Museu Paraense Emílio Goeldi), fundado em 1871, e do Museu Paulista, inaugurado em 1895, Schwarcz (1989, p. 65-66) tece as seguintes questões:

Definidos e pensados enquanto "locais de ciências", os museus ofereciam respostas a procedimentos considerados científicos, em contrapartida a outro tipo de produção que, lidando com o problema da raça, partia de métodos diversos. Se o tema perpassa outros debates - como a área legislativa - e espaços - como o da literatura -, também através dos museus é possível perceber a penetração desse tipo de questão. Assim, se em boa parte essas três instituições visavam um debate exterior e restrito, é a partir da questão racial que essa produção "vaza", encontrando respaldo no interior do panorama intelectual local.

É importante afirmar, portanto, a centralidade que o tema racial ocupou na agenda das ciências sociais brasileiras desde sua gênese. Ainda que não possamos resumir o debate - incluindo o da antropologia física - desse momento a esta questão, percebe-se que havia uma agenda mais ampla em curso já naquele período. Isso implicou no acionamento de diferentes ferramentas analíticas, e, por consequência, distintas aproximações com a questão passaram a ser mobilizadas, dentre elas, a antropologia física. Todavia, o tema não mobilizou exclusivamente os museus. Como bem apontam Souza e Santos (2012, p. 640),

no caso brasileiro, em consonância com o que ocorreu em outros países, o estabelecimento dos núcleos de investigação em antropologia física, com a consequente expansão das pesquisas e a construção de acervos, se deu a partir da segunda metade do século XIX, ainda nos tempos do Império, vindo a experimentar notável difusão nas primeiras décadas do século $\mathrm{XX}$ (Castro Faria, 1952; Cunha, 2002; Souza, 2011; Santos, 2012). Nesse período, em faculdades de medicina, museus de história natural, gabinetes de polícia, escolas e instituições de assistência social, a prática da antropologia física mobilizou antropólogos, médicos e naturalistas, que concentraram suas atividades no conhecimento das populações humanas, voltando suas angulares especialmente para a caracterização das populações brasileiras, sua constituição e diversidade biológica-racial. Enquadram-se nessa perspectiva as investigações antropofísicas sobre grupos indígenas, negros, sertanejos e imigrantes europeus; os debates sobre miscigenação racial, 
imigração e eugenia; e os estudos de biotipologia, medicina legal e antropologia jurídica.

Quero destacar com isso que, longe de constituir um capítulo menor na história da área no país, a questão da antropologia física foi um dos elementos basilares da formação da antropologia brasileira, num amplo diálogo com as ciências naturais. A questão para a qual pretendo contribuir com este artigo refere-se, justamente, à necessidade de repensarmos as relações entre a antropologia que ocupou um espaço central na formação das ciências sociais brasileiras até a primeira metade do século XX e a antropologia sociocultural, que passa a ganhar mais espaço enquanto esta outra declina no mesmo período. Notadamente, ao realizar um recorte regional, centrando na realidade de Santa Catarina, também é interessante perceber que houve nesse locus o desenvolvimento de outra temporalidade. Isso porque, ao passo que a antropologia física perdia paulatinamente espaço nos grandes centros de pesquisa no Brasil, ela passava a ganhar proeminência no contexto local, como veremos mais adiante com o advento do Instituto de Antropologia.

Parte significativa da obra de autores como Raimundo Nina Rodrigues (1862-1906), Edgard Roquette-Pinto (1884-1954), Álvaro Fróes da Fonseca (18901988), e mesmo, representando uma geração posterior, Arthur Ramos (1903-1949), desenvolveu-se nessa interface. Interessante perceber que os pesquisadores citados são, em sua totalidade, antropólogos que realizaram sua formação inicial no campo da medicina. Tal fato aponta também para os espaços de circulação e de formação intelectual comum a antropólogos neste período, que, de certo modo, possibilitava a inserção do debate próprio da antropologia física na agenda mais ampla da antropologia brasileira naquele momento.

Como bem destaca Keuller (2012), analisando especificamente o caso de Fróes da Fonseca, nesse período desenvolveu-se uma concepção particular de antropologia, situada nessa interface com a medicina. $\mathrm{E}$ apesar de reconhecida a divisão entre uma antropologia física e uma antropologia social e cultural, em muitos casos advogava-se a união entre os estudos anatômicos e os de antropologia, o que era percebido também como um passo relevante para a renovação dos estudos no campo da medicina.

Ressalta-se também que estamos nos referindo a um período em que as barreiras disciplinares estavam dispostas de outro modo. Como bem nos indica Corrêa (2013, p. 26):

A própria definição de cientistas sociais como antropólogos é muito recente e parece estar ligada tanto a razões de ordem prática, consequência das divisões disciplinares institucionalmente criadas - não só na universidade, mas também em fundações concessionárias de financiamento de pesquisas e nos órgãos governamentais da área da educação -, quanto a influências teóricas ou relações políticas no sentido amplo (Peirano, 1980). Essa distribuição disciplinar parece ter criado a necessidade de apropriação, ou 
exclusão, a posteriori, de pesquisas, pesquisadores ou temas em cada uma das áreas das ciências sociais que vão ganhando contornos mais nítidos pela ampliação de seus recursos humanos e institucionais. E parece também tornar inevitável a colocação das perguntas: como desembaraçar a antropologia dos laços que pareciam prendê-la tão fortemente, no passado, as disciplinas hoje dela tão diferenciadas como a medicina ou o direito, por exemplo? Como criar para ela um percurso, uma trajetória, bem definidos, cujo ponto de chegada sejam nós, antropólogos contemporâneos?

Penso que esta questão é emblemática para analisarmos o contexto no qual se insere o ensino de antropologia física no Brasil, bem como as transformações que vão sendo vivenciadas nas ciências sociais brasileiras. A partir da década de 1930, tivemos a criação dos primeiros cursos de ciências sociais no Brasilit, cujos resultados em termos de pesquisas produzidas pelas primeiras gerações de cientistas sociais profissionais serão sentidos nas décadas seguintes.

Esse fenômeno impacta diretamente os critérios de cientificidade e de legitimidade das pesquisas realizadas nessa seara, invertendo o eixo com relação ao locus de produção de conhecimento antropológico. Notadamente esse processo apenas se consolida plenamente no decorrer das décadas de 1960 e 1970, quando são criados os primeiros programas de pós-graduação no formato que conhecemos atualmente, o que implicou numa mudança expressiva das regras do jogo acadêmico no campo da antropologia. Como nos indica Garcia Jr. (2009, p. 438),

a restituição das condições sociais para enunciar e estabilizar um novo paradigma científico é um complemento indispensável à inteligibilidade do laço entre crítica interna das teorias pré-existentes e práticas intelectuais que permitem ultrapassar os limites precedentes (Heilbron, 2006). 0 estudo das características sociais e intelectuais dos participantes de controvérsias científicas, de suas alianças e de suas clivagens, de sua cooperação, constitui sem dúvida um bom revelador do modo como as relações de poder transnacionais inscrevem suas marcas na evolução dos modos de pensar ou dos sistemas cognitivos (Love 1996; Karady, 2008). Se toda pesquisa científica visa estabelecer hipóteses de validade universal, parece completamente vã a limitação do olhar sobre a circulação das ideias a relações bi-nacionais, por mais intensas que possam ter sido no passado.

Um exemplo significativo para pensarmos essas mudanças no campo acadêmico brasileiro é o de Heloisa Alberto Torres (1895-1977). Bastante reconhecida nacionalmente no campo da antropologia e de forte atuação no Museu Nacional, foi inclusive um dos membros da comissão julgadora do concurso de Arthur Ramos para a cátedra de Antropologia e Etnografia na Faculdade Nacional de Filosofia $(\mathrm{FNF})^{5}$. No entanto, quando Ramos morreu e foi aberto um novo concurso, "Dona Heloísa", como era conhecida (Corrêa, 1997), teve sua inscrição indeferida, por não atender aos requisitos do edital (Barros, 2008) .
4 Os primeiros cursos de ciências sociais criados no Brasil foram os da Escola Livre de Sociologia e Política de São Paulo (1933), da Universidade de São Paulo (1934), da Universidade do Distrito Federal (1935) e a Faculdade de Filosofia, Ciências e Letras do Paraná (1938) e da Faculdade de Filosofia, Ciências e Letras da Bahia (1941).

5 Além de ter sido membro do concurso para professor catedrático a que Arthur Ramos se submeteu em 1945, juntamente com José Farias Goés Sobrinho, Emílio Willems, Alvaro Froes da Fonseca, José Basto D’Ávila, ela também foi uma das pessoas que indicou o nome de Ramos para assumir a cadeira de antropologia, cargo para o qual foi nomeado como professor interino em 1939.

6 Apesar de reconhecido o notório saber de Heloisa Alberto Torres, o artigo $n^{\circ} 98$ do regimento da FNF, demandava a apresentação de curso superior cujo currículo contivesse disciplina correspondente à cátedra posta em concurso. Para uma melhor análise da trajetória acadêmica de Heloísa Alberto Torres, vide Miglievich-Ribeiro (2015). 
No interstício entre esses dois acontecimentos na vida de "Dona Heloisa", é importante indicar que Arthur Ramos criou na década de 1940, na Faculdade Nacional de Filosofia, um curso de aperfeiçoamento em antropologia e etnografia. Assim, poderia outorgar o título de doutor aos bacharéis que defendessem tese original depois de pelo menos dois anos de estudos, sob a orientação do professor catedrático da disciplina. Portanto, havia importantes mudanças em curso, que possuíam implicações sobre a forma como a antropologia estava se reorganizando academicamente no Brasil.

Tais mudanças implicaram num deslocamento institucional, no qual os museus perderam o espaço privilegiado que gozavam no campo da antropologia, especialmente para as universidades. Schwarcz (1989) aponta ainda que essa "decadência dos museus" se deveu não apenas às mudanças institucionais, como também à crítica teórica a um paradigma até então bastante consensual: o evolucionismo positivista, o que leva também a uma redefinição dos projetos e perspectivas originais presentes nessas instituições. Ainda segundo a autora, “considerados como locais de uma 'pré-ciência', restará aos museus nacionais o espaço delimitado de uma produção voltada exclusivamente às Ciências Naturais, cabendo em contrapartida às universidades a representação de um projeto enciclopédico e globalizante" (Ibidem, p. 71).

Esse deslocamento institucional e teórico também é acompanhado por um processo de delimitação disciplinar da antropologia que a distanciou das ciências naturais e a aproximou da sociologia (Peirano, 2000). Sem embargo, não se pode compreender que a antropologia física "desapareceu”, porém ela acabou sendo situada, quase que exclusivamente, dentro dos "tempos heroicos" da antropologia brasileira (Oliveira R., 2003).

Por outro lado, há de se considerar as questões trazidas por Farias (1999), ao indicar que a partir da década de 1930 ocorre um período de estabilidade na antropologia física no Brasil, uma estabilidade em termos de técnicas, métodos, objetivos e fins. Nesse período, instituições como o Museu Nacional continuaram a ser importantes centros de investigação e de formação de pesquisadores, em que pesem as transformações no próprio campo acadêmico.

Acredito que esse gesto de "apagamento" da antropologia física da história da antropologia brasileira, amiúde indicado como "pré-científico", deve ser compreendido num movimento mais complexo e amplo que envolve a história desta disciplina, abordando-se desde as disputas que ocorrem dentro do campo acadêmico (Bourdieu, 2011), uma vez que esse processo envolve também as disputas dos agentes que animam o campo. Neste sentido, são elucidativas as questões trazidas por Corrêa (1988, p. 14), referindo-se às pesquisas antropológicas desenvolvidas em instituições ligadas à educação, mas que também podem ser aplicadas, de certo modo, à questão da antropologia física:

Não acredito que as razões do esquecimento deste período tão interessante da história de nossa disciplina se devam apenas à descrença no tipo de antropologia que se fazia antes de hoje ou à alegada fragilidade institucio- 
nal dela naquele momento; penso antes que esse esquecimento deve ser atribuído ao fato de que tentamos buscá-la onde ela não podia estar, num "campo antropológico" ainda em constituição, ao invés de encontrá-la lá onde ela se praticava.

Mais que isso, ao que nos interessa mais diretamente neste artigo, é importante frisar que o amadurecimento desse debate teve temporalidades distintas no país. E ao mesmo tempo em que, em algumas regiões, as ciências sociais já estavam institucionalizadas no Ensino Superior, contando com cursos próprios, em outras (como é o caso de Santa Catarina), elas ainda estavam restritas a algumas cátedras isoladas, compondo parte da formação dos cursos oferecidos nas Faculdades de Filosofia. Ainda assim, havia um espaço relevante no ensino de antropologia física, articulada com outras cátedras situadas na interface entre essa disciplina e a antropologia cultural.

\section{As cadeiras de Ciências Sociais na Faculdade Catarinense de Filosofia}

A história do Ensino Superior em Santa Catarina inicia-se de forma mais incisiva na década de 1930, com a criação da Faculdade de Direito de Santa Catarina em 1932, e, posteriormente, das Faculdades de Ciências Econômicas (1943), Farmácia e Odontologia (1947) e Medicina (1955). No caso da FCF, criada ainda em 1951, suas atividades só foram iniciadas em 1955. Na ata de criação da FCF já é feita menção à sua possível incorporação a uma futura Universidade de Santa Catarina, bem como a existência de uma "Faculdade de Filosofia de Santa Catarina", criada em 1948, mas que nunca chegou a iniciar suas atividades.

Envolveram-se originalmente nesse projeto membros das elites culturais locais ${ }^{7}$, que circulavam em espaços diversos, tais como o Instituto Histórico e Geográfico de Santa Catarina (IHGSC), criado em 1896, o Colégio Catarinense, fundado em 1905, a Academia Catarinense de Letras, criada em 1924, além das demais faculdades já existentes àquele tempo, especialmente a Faculdade de Direito, espaço historicamente reservado à formação de quadros para o Estado e de reprodução das elites (Oliveira, 2018).

Deve-se acentuar também que naquele momento havia uma significativa expansão do ensino no estado, de forma que a FCF era compreendida como um espaço de formação de elites culturais e de professores para os cursos primário e secundário. Os egressos dos cursos das Escolas Normais eram percebidos como público preferencial a ocupar as vagas desta instituição. Já na década de 1930 havia sido iniciada uma reforma no sistema educacional do estado, acompanhando uma série de outras mudanças que ocorreram Brasil afora, visando modernizar o ensino e os cursos de formação de professores (Cury, 1988). A chamada "Reforma Trindade" (Decreto $n^{\circ} 713$, de 8 de janeiro de 1935), conduzida por Luiz Bezerra da Trindade, então Diretor da Instrução Pública do Estado de Santa Catarina, transformou as Escolas Normais em Institutos de Educação, introduzindo em seus currículos as chamadas "Ciências Fontes da Educação", tais como pedagogia, psicologia, biologia, história, filosofia e sociologia (Daniel, 2003) ${ }^{8}$.
7 Oficialmente foi no dia 8 de setembro de 1951, em reunião no salão nobre da Faculdade de Direito, que membros das elites locais, como o Desembargador Henrique da Silva Fontes, que fora presidente do IHGSC, Oswaldo Bulcão Viana, Victor da Luz Fontes, Monsenhor Frederico Hobold, Pe. João Alfredo Rohr - diretor do Colégio Catarinense, Pe. Alvino Braun e Oswaldo Rodrigues Cabral criaram oficialmente a FCF (Autor, 2018).

8 Importante rememorar que, em alguns casos no Brasil, na primeira metade do século XX, havia Escolas Normais que contavam, inclusive, com um gabinete de antropologia pedagógica, cuja discussão se aproximava substancialmente da antropologia física naquele momento (Autor, 2013). 
No requerimento do pedido de autorização de funcionamento que foi encaminhado para o governo federal é indicado o seguinte no item VIII:

Uma faculdade de filosofia está sendo, de há muito, almejada em Florianópolis, mormente pelos que, tendo concluído o curso normal, se dedicam ao magistério. É mesmo imperiosa necessidade para o meio, porquanto completará o bem organizado aparelhamento escolar catarinense, preparando-lhes professores para o ensino secundário e superior, além de dar oportunidade de estudos cientificamente orientados para os que, até aqui, só como autodidatas atingem as esferas da alta cultura. (Faculdade Catarinense de Filosofia, 1952, s/p).

Como já indicado, apenas em 1955 é que são iniciadas as atividades desta faculdade, tendo funcionado inicialmente os cursos de Filosofia, Geografia e História, Letras Clássicas, Letras Neolatinas e Letras Anglo-Germânicas. Esta era uma instituição privada, com uma forte orientação religiosa em sua estrutura, mas que contou com o apoio do poder público, inclusive através de seu financiamento.

O curso de Filosofia tinha as seguintes disciplinas distribuídas por ano: $1^{\circ}$ ) Introdução à Filosofia, Psicologia, Lógica, História da Filosofia; $2^{\circ}$ ) Psicologia, Sociologia, História da Filosofia; $3^{\circ}$ ) Psicologia, Ética, Estética, Filosofia Geral. Já no curso de Geografia havia as seguintes disciplinas: $1^{\circ}$ ) Geografia Física, Geografia Humana, Complementos de Geologia, História Moderna e Antropologia Física; $2^{\circ}$ ) Geografia Física, Geografia Humana, Geografia do Brasil, História Contemporânea e Antropologia Cultural; $3^{\circ}$ ) Geografia do Brasil, História Contemporânea, História do Brasil, História da América e História do Brasil. Por sua vez, no curso de história havia estas cadeiras: $1^{\circ}$ ) Introdução à História, Antropologia Cultural, Arqueologia e História Antiga; $2^{\circ}$ ) História Medieval, Cultura Ibérica, História da América, História do Brasil e Geografia Geral; $3^{\circ}$ ) História Moderna, História Contemporânea, História do Brasil, História da Arte e Etnografia do Brasil.

É interessante destacar nesse contexto que as primeiras turmas de história e geografia constituíam um único curso, que por sua vez possuía distintas habilitações, sendo uma delas a de "antropologia e arqueologia". Esse dado é revelador dos múltiplos sentidos que a antropologia assumiu ao longo do tempo, de modo que seria impreciso indicar os cursos de ciências sociais como único locus de formação de quadros para a antropologia no Ensino Superior, havendo uma substancial diferença acerca do modo como essa disciplina se regionaliza, associando-se a diferentes campos disciplinares a depender do contexto local.

As disciplinas de ciência sociais ficaram a cargo de Edmundo Accácio Moreira (1914-1986), bacharel em direito, como professor de sociologia; Oswaldo Rodrigues Cabral (1903-1978), doutor em medicina, professor de antropologia cultural; Pe. Alvino Bertholdo Braun (1908-1984), graduado em Filosofia e Teologia, professor de antropologia física; e Jaldyr Bhearing Faustino da Silva (1914-1994), por sua vez bacharel em direito, professor de etnografia do Brasil. À exceção de Moreira e Braun, os demais foram contratados também para outras 
disciplinas. Cabral para História da Antiguidade e Idade Média9 ${ }^{9}$ e Silva para História do Brasil.

Ressalta-se que afirmar que essas eram as disciplinas de ciências sociais possui um caráter mais "didático" que de precisão histórica neste texto, considerando-se que no Brasil se convencionou denominar ciências sociais as disciplinas de antropologia, ciência política e sociologia. Sem embargo, é importante ter em vista que a divisão disciplinar nesse momento ainda era bastante incipiente, e havia uma compreensão mais ampliada das ditas ciências sociais, abarcando disciplinas como história, economia, psicologia social, entre outras.

Em todo o caso, ao que nos interessa mais diretamente neste trabalho, o foco recairá sobre as disciplinas de antropologia física e etnografia do Brasil, como já anunciado, que parecem demarcar mais claramente uma descontinuidade com relação à tradição intelectual que se instaurou no Brasil, e que consolidou certa visão da história da antropologia.

Na FCF, as práticas cotidianas de ensino incluíam a produção de um "Relatório circunstanciado sobre o ensino ao seu cargo" (Faculdade Catarinense de Filosofia, 1957), que passa a ser exigido de seus professores já em 1956, no qual deveriam ser especificadas as partes lecionadas do programa. Não havia um modelo prévio de relatório a ser produzido, o que reverbera em certa heterogeneidade dos dados analisados. Este é o material empírico sobre o qual se debruça a análise que será feita no próximo tópico.

\section{O ensino de antropologia física e de etnografia do Brasil}

O padre Alvino Bertholdo Braun foi o escolhido para inaugurar a cátedra de antropologia física presente na FCF. Ele estava presente já na sessão de fundação desta instituição em 1951, o que aponta para o fato de que participou desse projeto desde sua concepção. Ainda nesse documento havia a indicação de que existia “(...) também pessoas capazes para constituírem o professorado inicial" (Faculdade Catarinense de Filosofia, 1951). Possivelmente esse ponto da ata se refere a alguns dos presentes nessa sessão, o que de fato acaba se concretizando. Interessante perceber que a formação da antropologia no Sul do Brasil teve uma participação ativa de religiosos. Como bem destaca Santos (1997), o perfil recorrente entre os primeiros catedráticos em antropologia nessa região era de agentes autodidatas e católicos. Deve-se destacar nesse contexto a figura do padre Alvino Bertholdo Braun, em Santa Catarina, e a do padre Ignácio Schmitz, no Rio Grande do Sul.

Braun era professor do Colégio Catarinense, um dos espaços de formação escolar das elites locais, tendo chegado a ser diretor da instituição. Sua atuação nessa escola se dava junto às ciências naturais. Era visto com um "naturalista", de modo que essa é possivelmente sua entrada para a antropologia física. Vale a pena rememorar o fato de que a antropologia física era percebida como o estudo biológico do homem, de tal modo que sua inserção como professor de ciências parecia credenciá-lo para assumir essa cátedra. Apesar de Braun possuir um trânsito mais evidente pelas ciências naturais, fica evidente que seu conhecimento transpunha
9 No caso de Cabral, sua mudança para a antropologia foi realizada por meio de um ofício em 1956 (sem data) do diretor em exercício padre Wener José Soell, endereçado ao diretor da Diretoria do Ensino Superior Dr. Jurandyr Lodi, no qual é requerida a transferência de Cabral para a cadeira de antropologia cultural, que naquele momento se encontrava vaga. 
essa delimitação disciplinar, uma vez que seu nome figura como membro da banca examinadora tanto das provas de geografia geral e do Brasil quanto de história geral e do Brasil, do concurso de habilitação para o ingresso na faculdade.

Com isso, também se chama atenção para o fato de que a antropologia era percebida ao mesmo tempo como uma disciplina pertencente ao âmbito das ciências naturais e das ciências sociais, o que refletia na divisão entre antropologia física e antropologia cultural. No curso de geografia, que tinha como um de seus eixos o estudo da relação entre "o homem e seu meio", tanto a antropologia física quanto a antropologia cultural estavam presentes. Isso parece apontar para uma compreensão alargada dos aspectos humanos que deveriam ser compreendidos dentro de um curso de formação de professores em geografia.

A indicação da antropologia física ainda no primeiro ano do curso de geografia poderia indicar que aquele era considerado um conhecimento básico para esta formação, cujos fundamentos poderiam ser acionados posteriormente. Sua concomitância com a disciplina de geografia física, também ofertada no segundo ano de curso, poderia indicar que também se articulavam questões como raça e meio físico nas discussões desenvolvidas, algo que teve um forte apelo no debate intelectual brasileiro, especialmente na passagem do século XIX para o XX.

De acordo com os relatórios, Braun iniciava seu curso realizando dez perguntas sobre conhecimentos básicos de antropologia que constariam nos programas do $1^{\circ}$ e $2^{\circ}$ ciclo do curso ginasial e colegial. Segundo seu relatório (sem data), apenas uma resposta foi "digna de apreço" (Braun, 1959, p. 1). Em outros relatórios, ele fala de 12 perguntas e de conhecimentos presentes apenas no $2^{\circ}$ ciclo do curso ginasial. Ele indica, em todos os relatórios, um parco conhecimento prévio de seus alunos sobre o conteúdo, iniciando, portanto, a partir do nível básico. Ainda segundo o professor, a "situação científica dos alunos" é de "quase todos sem base alguma para a matéria em apreço". É importante considerar que o ingresso no curso de geografia, assim como no de história, demandava dos alunos apenas o conhecimento de português, história geral e do Brasil, geografia geral e do Brasil, inglês ou francês, o que em parte pode explicar as lacunas formativas encontradas em seus alunos.

Havia uma baixa presença de alunos, ainda que se indique que aqueles que permaneceram no curso continuavam bastante assíduos. Os relatórios indicam uma variação entre dois e quatro alunos por turma. Embora houvesse uma previsão inicial de até quarenta vagas por curso, apenas no primeiro concurso de habilitação se conseguiu atingir o número de 80 alunos aprovados para todos os cursos, caindo nos anos seguintes para 35 (1956), 45 (1957), 49 (1958) e 31 (1959). Essa parca procura pelos cursos da faculdade como um todo pode explicar, em parte, o número diminuto de alunos no curso de antropologia física. Deve-se ainda considerar a perda de prestígio pela qual a disciplina vinha passando em nível nacional, já nesse período.

Também é sabido, por meio dos relatórios de ensino, que a FCF previa exames escritos e orais, e que a taxa de aprovação nesses exames era baixa. Havia, então, uma conjunção de fatores, como a decrescente procura pelos cursos da FCF e a 
alta seletividade de seus exames admissionais e de avaliação, que explicavam, ao menos em parte, o parco número de estudantes.

Dada a proximidade de Braun com as ciências naturais, bem como os encaminhamentos que ele demonstraria para sua cadeira, era de se supor que por conhecimento de antropologia ele tivesse em mente algo mais próximo da própria biologia, considerando as disciplinas presentes no currículo escolar naquele momento. Seu programa previa tanto uma parte prática quanto uma parte teórica. No que se refere à parte prática no primeiro semestre, ele indica o seguinte: "Foram dadas muitas aulas práticas a microscópio, mostrando elementos vivos e preparados de citologia e de histologia, tanto vegetal, para iniciação, quanto animal, atingindo a mitose em LUMBRECOIDE: Ascaris Bivalens” (Braun, 1957, p. 1).

Percebe-se aí a concepção de prática na antropologia física para Braun, vinculada, essencialmente, a um debate no campo da biologia, e das ciências naturais de modo mais geral. No que tange à parte teórica de seu programa, há maior detalhamento, indicando-se que:

Dadas as aulas introdutórias sobre a antropologia, começamos, no estudo citológico, a atingir o ÂMAGO de uma questão vital para o estudo da antropologia: A ORIGEM DA VIDA. Analisamos todas as teorias modernas, inclusive a de EICKSTEDT, que reduz a vida a simples FUNÇÃO DO ÁTOMO DE CARBONO.

Analisando as experiências de Spallazani, Pasteur, discutimos a possibilidade ou não da origem da vida da matéria inerte!

Fez-se também um estudo sobre o VÍRUS, a luz da revista moderna SCIENCE NEW LETTERS de 1955, 1956 e 1957.

A seguir fez-se estudo da célula como a força evolutiva do ANTHROPOS, que se desenvolveu DUMA ÚNICA CÉLULA fecundada num ser tão harmonioso e de funções tão variadas e complicadas.

Daí passamos para a histologia com as mesmas considerações, atingindo a organologia com suas medições.

Entramos também na EMBRIOLOGIA HUMANA a luz de quadros (Ranke)

A seguir foram tratadas as TEMATOLOGIAS HUMANAS e o célebre caso do médico brasileiro: Chapot-Prevost que agitou o senado nacional no seu tempo.

Estudamos detalhadamente: 0 sangue... hormonás--- indíces... pele, pelos e pelagem... pigmentação... a mão e o pé em estudo comparativo com os 
quadrumanos... e agora acabamos de tratar as funções de adaptação ao meio externo, aos acidentes, às infecções etc. Para entrarmos na genética antropológica e no estudo da origem do homem na terra, com os dados mais recentes. (Braun, 1957, p. 1).

Observa-se um programa que vai da citologia à origem do homem, possivelmente sendo esta a finalidade última da disciplina: pensar o homem em sua totalidade física. Seu esforço em produzir um programa atualizado se verificava não apenas pela referência constante a "teorias modernas" e "dados mais recentes", mas também a material em língua estrangeira, como no caso da revista Science News Letters - periódico americano iniciado em 1922, que publicava artigos breves voltados para a divulgação científica -, cuja aquisição se deu através da assinatura da Congregação Mariana Nossa Senhora do Desterro de Florianópolis.

Em outro relatório, Braun faz referência a um dos exames realizados com seus alunos, que consistia na realização de um trabalho "sobre a necessidade do conhecimento citológico para o estudo de antropologia" (Braun, 1958, p. 1). Dentre seus cinco alunos, apenas um recebeu o conceito "muito bom", outros dois receberam a avaliação "não atingiu o âmago da questão", e os dois restantes, o professor indica que são trabalhos idênticos, possivelmente indicando plágio. $O$ professor aponta ainda que a maior parte dos alunos nunca havia visto células vivas, ressaltando assim a relevância das aulas práticas.

Distando um pouco desse modelo mais enfaticamente ligado às ciências naturais, a disciplina de etnografia do Brasil encontrava-se numa situação limítrofe. Em relação inversa à posição que a disciplina de antropologia física ocupava na geografia, a etnografia do Brasil estava presente no último ano do curso de história. Isso pode indicar que esse era considerado um curso avançado, que pressupunha um conhecimento anterior em outras disciplinas, tais como antropologia cultural e arqueologia.

Jaldyr Bhearing Faustino da Silva possuía uma trajetória distinta de Braun, ainda que, assim como o professor de antropologia física, tenha se feito presente desde a primeira reunião para a criação da $\mathrm{FCF}^{10}$. Assim como tantos outros implicados no projeto dessa faculdade, ele tinha trânsito por outros espaços, tendo sido membro da Academia Catarinense de Letras, o que transparece o respaldo e a legitimação que gozava no âmbito local. Em momento posterior, tornou-se secretário de educação do estado de Santa Catarina nos anos de 1960, e professor de Estudos de Problemas Brasileiros, ${ }^{11}$ na Universidade Federal de Santa Catarina.

Como apontado anteriormente, Silva fora contratado também para lecionar história do Brasil, o que indica a produção de um diálogo intelectual distinto daquele elaborado por Braun. Sua aproximação com essa temática, portanto, se dava via história, disciplina na qual era reconhecido no estado. Seus relatórios eram mais "taquigráficos", se comparados com os de Braun, nos dando menos pistas sobre suas práticas cotidianas como docente. Porém, estão organizados de modo a conseguirmos perceber claramente como ele organizava os conteúdos a serem lecionados na disciplina de etnografia do Brasil, quais sejam:
$10 \mathrm{Na}$ ata da sessão de fundação da FCF consta seu nome como Capitão Jaldyr Bhearing Faustino da Silva, o que faz referência à sua patente militar.

11 No conjunto de transformações vivenciadas pelas reformas educacionais no período militar, destaca-se a criação da disciplina "Estudos de Problemas Brasileiros" por meio do Decreto $n^{\circ} 68.065$ de 1971 , que seria um desdobramento no nível superior da disciplina "Educação Moral e Cívica”. No caso da UFSC, chegou-se a ter uma "Coordenadoria de Estudos Brasileiros" alocada no 
1 - Estudo definindo Etnografia e distinguindo-a de Etnologia e Antropologia.

2 - Delimitação do campo de ação da Etnografia. Exemplos.

3 - Estudo das diversas teorias sobre a origem do homem americano.

4 - Histórico dos estudos etnográficos desde nosso descobrimento.

5 - O índio na literatura dos séculos XVI e XVII.

6 - Distribuições das nações e tribos pelo território brasileiro.

7 - Principais características das culturas das diversas nações e tribos.

Como parte das atividades, teriam ocorrido: a) orientação esquemática do assunto pelo professor; b) pesquisa pelos alunos com apresentação de trabalhos; c) discussão dirigida; d) conclusões finais pelo professor. Permanece aqui o pequeno número de alunos, em alguns casos apenas dois, em outros um número um pouco maior, contando com alunos do curso de história e de geografia.

Frisa-se também que no relatório referente ao ano de 1959 há o acréscimo de mais um tópico no programa da disciplina intitulado "Estudos do negro". A inserção desta temática demonstra afinidade com uma discussão mais ampla que vinha sendo realizada no campo das ciências sociais naquele período. Como bem demonstra Villas Bôas (2007), esse era um dos temas mais relevantes naquele momento, seja no campo da antropologia, seja no campo da história ou sociologia.

A relação que essa disciplina estabelecia com a de antropologia cultural era mais próxima, referindo-se inclusive ao conceito de cultura, que era o primeiro ponto do programa de ensino do professor Oswaldo Rodrigues $\mathrm{Cabral}^{12}$ em sua cadeira. Todavia, aparentemente, essa era uma relação não apenas de proximidade, mas também de demarcação de fronteiras, como se pode perceber pelo primeiro tópico centrado na distinção entre a etnografia, a antropologia e a etnologia. Portanto, pressupunha não apenas continuidades, mas também rupturas entre esses campos disciplinares.

Essa relação entre a antropologia e a etnografia também nos remete às diferenciações existentes entre as distintas matizes de produção do pensamento antropológico, como bem podemos observar ante as várias nomenclaturas utilizadas para as diferentes tradições nacionais, tais como: Antropologia Social (Inglaterra e parte da Europa); Antropologia Cultural (Estados Unidos); Etnologia (França), entre outras. Observa-se, portanto, que o desenvolvimento concomitante das discussões no campo da antropologia física/biológica e da etnologia/antropologia sociocultural levam a questões diferentes em seus campos, mas que eventualmente se tocam.

Aparentemente a concepção de etnografia existente nessa disciplina era bem mais ampla que aquela que começava a se esboçar no campo da antropologia social e cultural, compreendendo-se não como um recurso metodológico e interpretativo, mas sim como um campo relativamente autônomo, que se desdobrava em um campo disciplinar. Podemos colocar em outros termos essa questão ao pensarmos que essa disciplina, aparentemente, estava preocupada mais em analisar e discutir certo material etnográfico acumulado sobre a sociedade e a cultura brasileiras, do que realizar um debate em torno dos fundamentos metodológicos departamento de geociências, que contava com 15 professores na década de 1980 (Thiago; Borges Filho; Martorano, 1981).

12 Oswaldo Cabral foi possivelmente a figura de maior proeminência na formação do campo da antropologia em Santa Catarina, tornando-se o primeiro catedrático nessa área. Foi o responsável pela fundação do Instituto de Antropologia na década de 1960, já na Universidade Federal de Santa Catarina, à qual a FCF fora incorporada (Oliveira; Barbosa, 2018). 
da pesquisa etnográfica.

Apesar de parecerem programas de disciplinas substancialmente distintos, o de antropologia física e o de etnografia do Brasil, acredito que haja elementos que demarcam certa aproximação entre essas cadeiras, ao mesmo tempo em que se distanciam do que se tornou hegemônico na história da antropologia brasileira.

Não podemos esquecer que apesar do substancial afastamento que se observa entre a antropologia física e a sociocultural no Brasil a partir da segunda metade do século XX, em Santa Catarina houve o desenvolvimento de um cenário bastante idiossincrático, marcado pela fundação do Instituto de Antropologia na década de 1960. Tal instituto possuía três seções: arqueologia, antropologia física e antropologia cultural. Sendo assim, podemos inferir que no contexto específico do desenvolvimento da antropologia em Santa Catarina os diálogos entre a antropologia física e a antropologia cultural perduraram um pouco mais que no resto do Brasil, uma vez que o projeto do Instituto de Antropologia se manteve até a reforma universitária de 1968, transubstanciando-se posteriormente em museu.

Partindo de esquemas teóricos distintos, tanto a disciplina de Braun quanto a de Silva visavam, em última instância, debater a "origem do homem", ainda que no último caso houvesse uma maior especificidade sobre o homem americano. Essa parecia ser uma questão central que, em grande medida, justificaria a presença de tais disciplinas nos cursos de geografia e de história. Em ambas as formações estava presente a disciplina de antropologia cultural, portanto, havia um diálogo estabelecido entre essas disciplinas, que reverberava uma clara distinção entre o tipo de conhecimento produzido no campo da antropologia cultural e aquele produzido pela antropologia física e pela etnografia.

Esse movimento de delimitação de conhecimento, e também de distanciamento que essas disciplinas demarcaram em relação à antropologia cultural, pode explicar, ao menos em parte, o local secundário que elas passaram a ocupar no período posterior. Assim, na década de 1960, Oswaldo Cabral fundou o Instituto de Antropologia, o qual, claramente assentado numa perspectiva social e cultural da antropologia, tornou-se a instituição que centralizava a discussão e a produção de conhecimento antropológico.

Claro que aí é importante reconhecer que o campo acadêmico depende não apenas da competência científica de seus agentes, como também da competência social (Bourdieu, 2011), de modo que a inserção mais significativa de Cabral na estrutura universitária (ele chegou a ser diretor da FCF) possibilitou a consolidação de um determinado projeto de antropologia em Santa Catarina, em detrimento de outros. Porém, deve-se considerar aqui que o Instituto de Antropologia não ignorou essa discussão; pelo contrário, acabou incorporando-a. Parte dos conteúdos de antropologia física passaram a integrar o curso de antropologia, o que ia na direção contrária de maior delimitação do campo, que aparentemente era apontada pelos programas dos professores Braun e Silva. 


\section{Considerações finais}

Este breve trabalho buscou trazer alguma contribuição ao debate sobre a história da antropologia no Brasil, explorando certos aspectos dessa disciplina secundarizados em relação aos paradigmas que se tornaram hegemônicos. Como apontam Durham e Cardoso (1961, p. 96), no balanço que elas produzem acerca do ensino de antropologia no Brasil, o ensino de antropologia física se restringiria “(...) apenas a informações gerais e, quando muito, a uma caracterização dos problemas centrais da disciplina, que complementam uma formação voltada para as Ciências Sociais".

A contribuição deste trabalho encontra-se ainda em dois deslocamentos realizados: $1^{\circ}$ ) um geográfico, que nos possibilita perceber a realidade das ciências sociais fora dos grandes centros, captando as diversas temporalidades existentes, uma vez que na década de 1950 já havia cursos de ciências sociais autônomos e alguns de pós-graduação no eixo Rio-São Paulo, porém, em Santa Catarina essas disciplinas estavam restritas a algumas cátedras que ofereciam uma formação complementar em relação aos cursos de história e geografia; $2^{\circ}$ ) outro de caráter metodológico, ao pensar a história destas disciplinas não a partir das obras produzidas pelos pesquisadores, tampouco pelos temas de pesquisa, mas sim pelo cotidiano do ensino, o que nos foi possível acessar através dos relatórios de ensino produzidos pelos docentes responsáveis pelas disciplinas na década de 1950 .

Avançar neste debate implica também destacar as continuidades e descontinuidades existentes no campo, apontando para certa concepção e rotinização do conhecimento antropológico em determinado contexto local. Esse movimento visibiliza a pluralidade de tradições antropológicas, assim como as disputas em campo, ao apontar para perspectivas e práticas que perderam espaço ao longo do tempo.

Acredito que o relevante a se destacar aqui é que as aulas de antropologia física de Braun e de etnografia do Brasil de Silva, em que pesem as dificuldades didáticas encontradas, visavam tornar acessíveis determinados conhecimentos nessa área no nível local, os quais os alunos não conseguiam obter anteriormente. A ideia de formação de elites culturais, nesse contexto, é profundamente importante, uma vez que significa que tais conhecimentos foram considerados relevantes para a sua formação .

Observou-se que as transformações ocorridas no campo da antropologia, seja no nível local seja no nível nacional, implicaram em uma inflexão da delimitação disciplinar e na expansão do ensino das disciplinas de antropologia física e etnografia do Brasil na FCF. A consolidação desse processo se completa na década de 1970, com a criação do curso de ciências sociais na Universidade Federal de Santa Catarina, à qual a FCF foi incorporada, e onde não havia nenhuma cadeira situada nesse campo disciplinar.

O "apagamento" dessas disciplinas da história da antropologia em Santa Catarina deve ser compreendido, portanto, no contexto das transformações do campo acadêmico brasileiro, e das ciências sociais em particular. Porém, a análise mais cuidadosa não nos permite simplificar a questão situando tais disciplinas como 
Amurabi Oliveira

"pré-científicas", reconhecendo-se sim que os debates produzidos naquele contexto - com destaque para a questão da origem do homem - foram fundamentais para a formação do campo da antropologia, tanto em Santa Catarina como no Brasil.

Recebido: 21/05/2019

Aprovado: 02/09/2019 
Amurabi Oliveira

\section{Referências}

BARROS, L. O. C. Arthur Ramos e as dinâmicas sociais de seu tempo. Maceió: EdUFAL, 2008.

BRAUN, A. Relatório de Ensino de Antropologia Física. Florianópolis, SC: Faculdade Catarinense de Filosofia, 1957.

BRAUN, A. Relatório de Ensino de Antropologia Física. Florianópolis, SC: Faculdade Catarinense de Filosofia., 1958.

BRAUN, A. Relatório de Ensino de Antropologia Física. Florianópolis, SC: Faculdade Catarinense de Filosofia., 1959.

BOURDIEU, P. Homo academicus. Florianópolis: EdUFSC, 2011.

CORRÊA, M. A revolução das normalistas. Cadernos de Pesquisa, n. 66, p. 13-24, 1988.

CORRÊA, M. Dona Heloisa e a pesquisa de campo. Revista de Antropologia, v. 40, n. 1, p. 11-54, 1997.

CORRÊA, M. Ilusões de liberdade: a escola Nina Rodrigues e a Antropologia no Brasil. Rio de Janeiro: Fiocruz, 2013.

CURY, C. R. Ideologia e educação brasileira: católicos e liberais. São Paulo: Cortez, 1988.

DANIEL, L. S. Por uma psico-sociologia educacional: a contribuição de João Roberto Moreira para o processo de constituição científica da Pedagogia nos cursos de formação de professores catarinenses nos anos de 1930 e 1940. 163 p. Dissertação (Mestrado em Educação) - Centro de Ciências da Educação. Universidade Federal de Santa Catarina, Florianópolis, 2003.

DURHAM, E. R.; CARDOSO, R. C. L. O ensino de Antropologia no Brasil. Revista de Antropologia, v. 9, n. 1-2, p. 91-108, 1961.

FACULDADE CATARINENSE DE FILOSOFIA. Ata de fundação da FCF, 8 de setembro de 1951. Florianópolis, 1951.

FACULDADE CATARINENSE DE FILSOOFIA. Atas da direção da Faculdade. Florianópolis, 1957.

FACULDADE CATARINENSE DE FILOSOFIA. Relatório concernente à verificação para efeito de reconhecimento da Faculdade Catarinense de Filosofia. Requerimento para autorização de funcionamento da FCF - 16 de julho de 1952. Volume II.

FARIA, L. C. Antropologia: escritos exumados 2 - dimensões do conhecimento antropológico. Niterói: EDUFF, 1999.

GARCIA JR., A. Fundamentos empíricos da razão antropológica: a criação do PPGAS e a seleção das espécies científicas. Mana, v. 15, n. 2, p. 411-447, 2009.

KEULLER, A. T. A. M. Entre antropologia e medicina: uma análise dos estudos antropológicos de Álvaro Fróes da Fonseca nas décadas de 1920 e 1930. Boletim do Museu Paraense Emílio Goeldi. Ciências Humanas, v. 7, n. 3, p. 687-704, 2012.

MIGLIEVICH-RIBEIRO, A. M. Heloísa Alberto Torres e Marina de Vasconcellos: pioneiras na formação das ciências sociais no Rio de Janeiro. Rio de Janeiro: Editora da UFRJ, 2015.

OLIVEIRA, A. O lugar da antropologia na formação docente: um olhar a partir das Escolas Normais. Pro-Posições, v. 24, n. 2, p. 27-40, 2013.

OLIVEIRA, A. O ensino de ciências sociais na Faculdade Catarinense de Filosofia. Ciências Sociais, Unisinos, v. 54, n. 1, p. 117-125, 2018. 
Amurabi Oliveira

OLIVEIRA, A.; BARBOSA, I. Oswaldo Rodrigues Cabral e a formação da antropologia em Santa Catarina. Áltera: revista de antropologia, v. 1, n. 6, p. 37-54, 2018.

OLIVEIRA, R. C. Sobre o pensamento antropológico. Rio de Janeiro: Tempo Brasileiro, 2003.

PEIRANO, M. A antropologia como ciência social no Brasil. Etnográfica, v. 4, n. 2, p. 219-232, 2000.

SCHWARCZ, L. K. M. O nascimento dos museus. In: MICELI, S. (Org.). História das Ciências Sociais no Brasil, v. 1. São Paulo: Vértice/Idesp/Finep, 1989. p. 20-71.

SOUZA, V. S.; SANTOS, R. V. Corpos, medidas e nação: antropologia física na capital da República brasileira na primeira metade do século XX Boletim do Museu Paraense Emílio Goeldi. Ciências Humanas, v. 7, n. 3, p. 639-643, 2012.

THIAGO, A. G. S.; BORGES FILHO, N.; MARTORANO, D. A disciplina Estudo de Problemas Brasileiros na UFSC. 1981. Disponível em: https://periodicos.ufsc.br/index.php/revistacfh/article/download/23746 /21313. 